\title{
Loss of specificity in basal ganglia related movement disorders
}

\author{
Maya Bronfeld' ${ }^{1}$ and Izhar Bar-Gad ${ }^{1,2 *}$ \\ 1 The Leslie and Susan Gonda (Goldschmied) Multidisciplinary Brain Research Center, Bar-llan University, Ramat-Gan, Israel \\ 2 The Mina and Everard Goodman Faculty of Life Sciences, Bar-Ilan University, Ramat-Gan, Israel
}

Edited by:

Charles J. Wilson, University of Texas at San Antonio, USA

Reviewed by:

Peter Redgrave, University of Sheffield, UK

Thomas Wichmann, Emory University, USA

\section{*Correspondence:}

Izhar Bar-Gad, Gonda Brain Research

Center, Bar-llan University, Ramat-Gan 52900, Israel.

e-mail: izhar.bar-gad@biu.ac.il
The basal ganglia (BG) are a group of interconnected nuclei which play a pivotal part in limbic, associative, and motor functions. This role is mirrored by the wide range of motor and behavioral abnormalities directly resulting from dysfunction of the BG. Studies of normal behavior have found that $B G$ neurons tend to phasically modulate their activity in relation to different behavioral events. In the normal BG, this modulation is highly specific, with each neuron related only to a small subset of behavioral events depending on specific combinations of movement parameters and context. In many pathological conditions involving BG dysfunction and motor abnormalities, this neuronal specificity is lost. Loss of specificity (LOS) manifests in neuronal activity related to a larger spectrum of events and consequently a large overlap of movementrelated activation patterns between different neurons. We review the existing evidence for LOS in BG-related movement disorders, the possible neural mechanisms underlying LOS, its effects on frequently used measures of neuronal activity and its relation to theoretical models of the BG. The prevalence of LOS in a many BG-related disorders suggests that neuronal specificity may represent a key feature of normal information processing in the BG system. Thus, the concept of neuronal specificity may underlie a unifying conceptual framework for the BG role in normal and abnormal motor control.

Keywords: basal ganglia, information encoding, movement, Parkinson's disease, dystonia, dyskinesia,Tourette syndrome

\section{THE BASAL GANGLIA}

The basal ganglia $(\mathrm{BG})$ are a group of interconnected nuclei which are reciprocally connected with the cortex and some brainstem nuclei to form partially closed loops (Joel and Weiner, 1994; Haber et al., 2000), and thus have an important role in normal motor, associative, and limbic function (Alexander et al., 1986; Alexander and Crutcher, 1990a). Information is sent from multiple parts of the cortex and thalamus to the BG input structures: the striatum and the subthalamic nucleus (STN). This input is integrated and processed via multiple pathways within the $\mathrm{BG}$ until reaching the output structures: the globus pallidus internus (GPi) and the substantia nigra pars reticulata (SNr; Albin et al., 1989; DeLong, 1990). The output of the BG is conveyed to the thalamus and to multiple brainstem structures. The loops through the BG are closed by projections from the thalamic nuclei receiving $B G$ innervation to frontal cortical areas and by projections from the brainstem nuclei to thalamic nuclei projecting back to BG input structures (Carpenter et al., 1976; Kim et al., 1976; Nambu et al., 1988; McHaffie et al., 2005). Anatomical studies have found that the information going through the BG is segregated into partially overlapping motor, associative, and limbic loops, defined by the cortical area from which the BG input arises and the type of information it processes (Alexander et al., 1986; Haber et al., 2000). The motor BG domain is the most studied to date and will be the main focus of this review.

The role of the BG in behavioral modulation has historically been inferred using two complementary methods: the activity of BG neurons during normal behavior (Mink, 1996), and behavioral abnormalities associated with BG dysfunction (Crossman, 1987).

\section{NORMAL BASAL GANGLIA MOVEMENT-RELATED ACTIVITY}

Early animal studies found that neurons in the BG phasically change their activity in close temporal relation to different movements, primarily of the contralateral limbs (DeLong, 1971, 1972, 1973). Detailed examinations revealed that the activity of BG neurons was related to different parameters of movements such as direction, velocity, amplitude, muscular load, and force (Georgopoulos et al., 1983; Crutcher and DeLong, 1984; Brotchie et al., 1991a; Mink and Thach, 1991a; Turner and Anderson, 1997). Later studies found that some BG neurons also encode non-motor aspects of the behavior, such as external and internal cues and triggers, type of reinforcement and movement context (Alexander and Crutcher, 1990b; Brotchie et al., 1991b; Mushiake and Strick, 1995; Turner and Anderson, 2005). Notably, the activity of many BG neurons was found to be related not to a single movement parameter, but rather to combinations of motor and contextual features (Mink and Thach, 1991b; Arkadir et al., 2004). Overall, BG neuronal encoding of most of these behavioral parameters is not spatially organized, i.e., neurons encoding the same parameter do not tend to cluster together, and similarly, closely located neurons often encode different behavioral parameters (DeLong et al., 1985; Mink and Thach, 1991a). The only exception to this rule is the somatotopic organization that can be found in the BG. Neurons related to movements of the leg, arm, or face tend to be clustered together in their respective somatotopic territories (Alexander and DeLong, 1985; DeLong et al., 1985; Wichmann et al., 1994). This highly specific and mostly spatially diffuse nature of BG movement-related neuronal activity is likely the cause for 
the relatively small number of movement-related neurons found in intact animals (DeLong, 1971). Indeed, the relative fraction of task-related neurons and the observed patterns of neuronal selectivity are highly dependent on the exact motor and associative parameters of the experimental motor tasks (DeLong, 1973; Mink and Thach, 1987).

Highly specific movement-related activity modulations have been found in all processing levels of the BG, but their expression differs depending on the basic firing characteristics of the neurons in each structure. The projection neurons of the striatum (BG input stage) are quiescent most of the time, and fire a short burst of activity in response to preferred events (DeLong, 1973; Liles, 1985). In contrast, neurons in the globus pallidus externus (GPe, BG internal stage) and internus (BG output stage) are tonically active with a high-frequency baseline firing rate, and their movementrelated activity is either a decrease or an increase in firing rate, with increases more common in intact animals (DeLong, 1971; Turner and Anderson, 1997).

\section{BASAL GANGLIA DYSFUNCTION}

The importance of the BG system is evidenced by the severe behavioral abnormalities associated with both experimentally induced and naturally occurring BG dysfunction. Selective anatomical and functional abnormalities in the cortico-BG system have been observed in patients suffering from disorders such as Parkinson's disease (Agid, 1991), Huntington's chorea (Glass et al., 2000; Deng et al., 2004), dystonia (Marsden et al., 1985), and motor tics (Singer and Minzer, 2003), which were therefore considered "BG-related movement disorders." Animal models and anecdotal findings in human patients confirmed that localized dysfunctions (inactivation or disinhibition) of different parts of the BG could directly induce behavioral abnormalities similar to the symptoms observed in these disorders (Martin and Alcock, 1934; Crossman et al., 1988; Hamada and DeLong, 1992; Grabli et al., 2004; Desmurget and Turner, 2008; McCairn et al., 2009; Bronfeld et al., 2010). The exact nature of the abnormal symptoms has been related to the type and location of the BG dysfunction.

\section{NEURONAL LOSS OF SPECIFICITY}

Different BG-related disorders are associated with a wide variety of clinical manifestations and physiological abnormalities. Despite these differences, one physiological phenomenon is common to many BG-related disorders: neuronal loss of specificity (LOS). In many of these pathological conditions, individual BG neurons lose their characteristic selective movement-related activity profiles and instead display similar activity modulations related to a broader range of behavioral events (Figure 1). In this section we review evidence for BG LOS in human patients and in animal models of the major BG-related diseases.

\section{PARKINSON'S DISEASE}

Parkinson disease (PD) is the most extensively studied BG-related disorder, and has inspired many of the current models of the BG. PD is a neurodegenerative movement disorder characterized by hypokinesia (immobility, slowed and small movements), muscle rigidity and tremor (Parkinson, 1817; Agid, 1991). Loss of dopaminergic innervation to the BG was identified as the basic pathology underlying many of the motor symptoms of PD (Hornykiewicz, 1966), which can be replicated in the non-human primate model of PD. Administration of 1-methyl-4-phenyl1,2,3,6-tetrahydropyridine (MPTP) to monkeys leads to selective death of dopaminergic neurons and mimics many clinical symptoms of the disorder (Burns et al., 1983). This model has enabled extensive study of the neurophysiological changes associated with PD (Jenner, 2003). Recording of neuronal activity from the BG of human PD patients has recently become possible due to the use of
A

\section{Specific encoding}

B

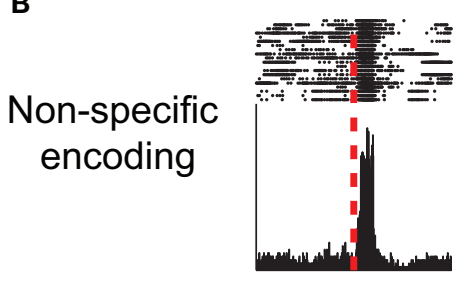

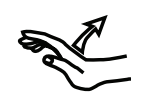
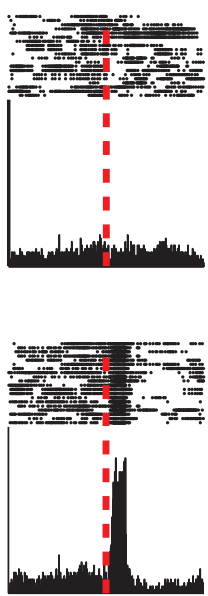
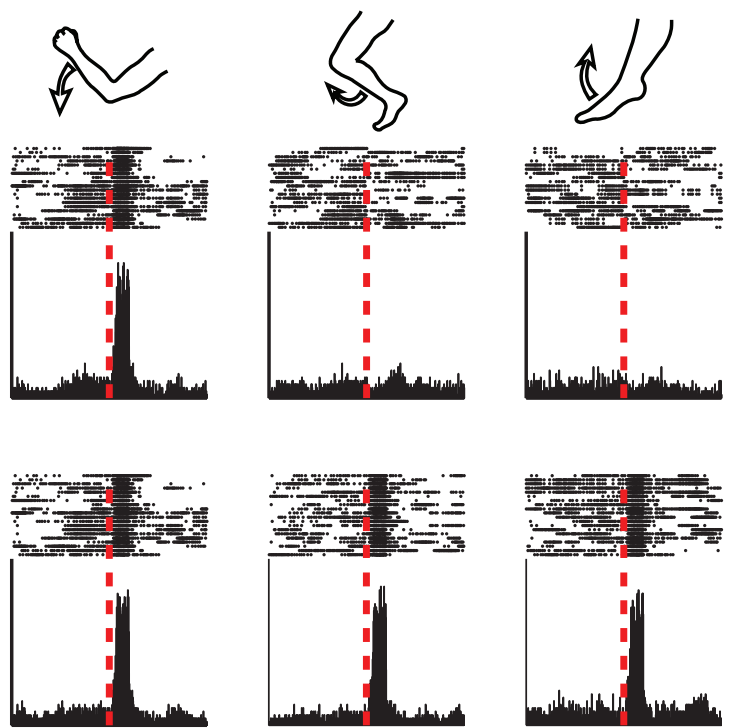

FIGURE 1 | Neuronal specificity. Peri-event time histograms and raster plots of the activity of a single neuron around the onset-time of different movements (simulated data), illustrating the concept of neuronal specificity. (A) Specific encoding, the neuron displays rate changes only in relation to movements of a single joint. (B) Non-specific encoding, the neuron displays similar rate modulations related to movements of multiple joints. 
stereotactic neurosurgical intervention procedures targeting the GPi or the STN to ameliorate PD symptoms (Anderson et al., 2005; Rodriguez-Oroz et al., 2005). While this type of research is limited by the lack of control data from healthy subjects, it is often compared to observations made in non-human primates. Studies of BG movement-related activity have revealed both direct and indirect evidence of neuronal LOS in PD. The relative number of pallidal neurons displaying movement-related activity is substantially larger in MPTP-treated monkeys and in human PD patients compared with normal monkeys (Filion et al., 1988; Williams et al., 2005; Baker et al., 2010; Erez et al., 2011). Studies also found that in these parkinsonian states a large fraction of neurons display activity modulations related to movements of more than a single body part (Figure 1), including activity modulations related to movements of both the arm and the leg, movements of multiple joints and movements of the ipsilateral limbs (Filion et al., 1988; Taha et al., 1996; Boraud et al., 2000; Levy et al., 2001; Baker et al., 2010). However, some level of somatotopic organization is still preserved in the parkinsonian state, despite the formation of a larger somatotopical overlap (Rodriguez-Oroz et al., 2001; Theodosopoulos et al., 2003; Baker et al., 2010). PD-related LOS was also observed in the activity of thalamic neurons receiving BG output (Pessiglione et al., 2005).

\section{DYSTONIA}

Dystonia is a movement disorder characterized by intermittent and sustained muscle contractions, often involving co-contraction of agonist and antagonist muscles, which leads to involuntary abnormal movements and postures (Fahn and Eldridge, 1976). Dystonia may appear in a variety of pathological conditions, but is most often associated with a lesion or dysfunction of the cortico-BG system (Marsden et al., 1985; Guehl et al., 2009). Evidence for LOS in some types of focal dystonia were found in human patients using non-invasive techniques: transcranial magnetic stimulation (TMS) and functional magnetic resonance imaging (fMRI). These studies found abnormal alterations in the somatotopic organization of the cortico-striatal circuits, mainly in the form of increased overlap between areas, suggesting reduced specificity of the neural representation (Tamburin et al., 2002; Delmaire et al., 2005; Quartarone et al., 2008).

Recordings of neurophysiological activity in non-human primate models of more severe or generalized types of dystonia found that dystonia was associated with a systematic increase in the sensorimotor responsiveness of BG neurons with increased multi-joint, multi-limb, and multi-directional movementrelated activity (Guehl et al., 2009). Similar activity patterns were observed in recordings of neuronal activity in the GPi of dystonia patients (Lenz et al., 1998; Vitek et al., 1999; Chang et al., 2007), obtained during neurosurgical interventions for the treatment of severe dystonia (Coubes et al., 2000). Studies also found that the gross somatotopic organization, such as the separation between "arm" and "leg" areas, was maintained in the pallidum of dystonia patients (Chang et al., 2007), but the more subtle somatotopic organization that can be detected in sensorimotor cortical and thalamic areas, such as the spatially separated representations of different digits, was disturbed (Bara-Jimenez et al., 1998; Lenz et al., 1999).
Notably, some degree of dystonia often appears as a comorbid symptom both in human PD patients and in MPTP-treated primates (Tabbal et al., 2006; Del and Albanese, 2008; Wickremaratchi et al., 2009). The relative contribution of each comorbid disorder to the observed LOS in such cases is currently unknown.

\section{TICS}

Motor tics are repetitive involuntary brief muscle contractions that can appear either as the primary or a secondary symptom in several human movement disorders, most notably Tourette syndrome (TS; Kurlan, 2004). Tics are primarily associated with dysfunction of the BG input structure - the striatum (Singer and Minzer, 2003). Our studies (McCairn et al., 2009; Bronfeld et al., 2011) of BG neuronal activity in a non-human primate model of motor tics suggested that tics were also associated with BG LOS (Figure 2). In the striatum, tic-related activity was somatotopically organized, but almost all neurons recorded from the tic-related somatotopical territory displayed non-specific tic-related activity (Bronfeld et al., 2011). In the GPe and GPi, a larger than normal fraction of recorded neurons (over 70\%) demonstrated strong activity modulations related to tic-movements, even though tics were confined to one or a few muscles (McCairn et al., 2009). Similar findings were observed in the GPi of TS patients undergoing neurosurgery (Zhuang et al., 2009). Tic-related neurons were diffusely distributed within GPe and GPi, with no spatial organization of neurons expressing similar types of tic-related activity (Figure 2), suggesting a loss of the somatotopic organization in these structures (McCairn et al., 2009; Zhuang et al., 2009).

\section{CHOREA}

Chorea is a hyperkinetic symptom characterized by involuntary and irregular continuous movements (Wild and Tabrizi, 2007), which appears in several BG-related disorders (Crossman, 1987) such as Huntington's disease (HD; Marshall, 2004), L-dopa-induced dyskinesia in PD patients (Bezard et al., 2001), and hemiballism (Martin and Alcock, 1934). The heterogeneity of the background conditions associated with chorea makes it difficult to characterize the abnormal neuronal activity specifically related to chorea, rather than to the accompanying motor dysfunctions. One study of pallidal movement-related activity in HD patients reported that the proportion of movement-related GPi cells was similar in their samples of HD and PD patients, but lower than reported for parkinsonian primates, and multi-joint responses were not found in HD (Starr et al., 2008). Unfortunately, the results of this study are severely confounded by the small sample size (only one HD patient). Two other studies of choreic movements induced in non-human primates by either systemic administration of a dopaminergic agonist (Nevet et al., 2004) or local GPe microinjections of a GABA-A antagonist (Bronfeld et al., 2010) reported no increase of correlated pallidal activity which might have suggested movement-related LOS. However, our work on experimentally induced chorea in nonhuman primates suggests that during a choreic state some pallidal neurons may demonstrate phasic activity modulations related to a wider than expected range of behavioral events associated with a sensorimotor task, but these data remain anecdotal (Bronfeld et al., 2010). Thus, additional studies both in human patients and in animal models are required to establish the degree of LOS in chorea. 

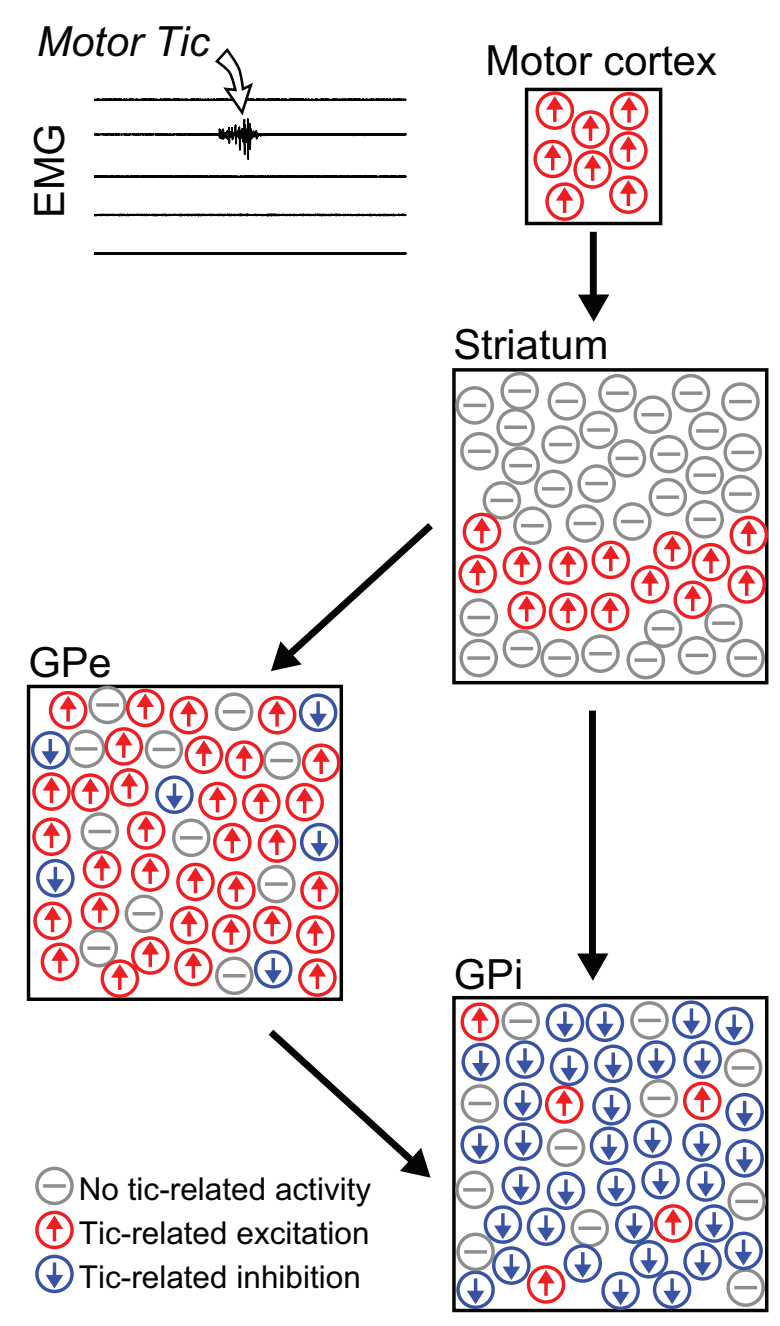

FIGURE 2 | Non-specific tic-related neuronal activity. Schematic illustration depicting the relative frequency and spatial distribution of neuronal activity patterns in the cortico-basal ganglia system related to motor tics confined to a single muscle group (Bronfeld et al., 2011). In the striatum, tic-related activity was confined to the somatotopical territory of the tic location, but almost all projection neurons recorded from that territory displayed non-specific tic-related bursts of activity. In the pallidum, tic-related activity was detected in a very large and spatially diffuse subpopulation of neurons. Tic-related excitations and inhibitions were the predominant responses in GPe and GPi neurons, respectively.

\section{BEHAVIORAL DISORDERS}

While most studies of BG function and dysfunction have focused on their role in motor control, there is increasing interest in the involvement of the BG in associative and limbic functions, particularly in the context of BG-related behavioral disorders. Dysfunction of the cortico-BG system have been consistently found in disorders of behavioral regulation such as obsessive-compulsive disorder (OCD) and attention-deficit-hyperactivity disorder (ADHD; Swanson et al., 1998; Graybiel and Rauch, 2000; Whiteside et al., 2004; di Michele et al., 2005). Moreover, these disorders show high comorbidity rates with other BG-related movement disorders (Swanson et al., 1998; Murphy et al., 2000; Anderson et al., 2001; Peterson et al., 2001). Animal studies have found that the same local
BG pharmacological manipulation that induces abnormal movements can induce complex abnormal behaviors such as stereotypy and hyperactivity/attention-deficit reminiscent of OCD and ADHD respectively, depending on the site and type of innervation within the BG (Yoshida et al., 1991; Grabli et al., 2004; Worbe et al., 2008). Taken together, this suggests that a similar BG neurophysiological dysfunction may underlie both motor and behavioral disorders, with the different manifestations determined by the identity of the affected functional territory and extent of the pathology (Joel, 2001). It is still unknown whether LOS is a feature of BG-related behavioral disorders, but there is a strong possibility given the similar neuronal substrates of the motor, limbic, and associative BG circuits.

\section{MECHANISMS UNDERLYING NEURONAL SPECIFICITY}

Patterns of event-related neuronal activity are determined by spatial and temporal integrations of inputs to the neuron. Neurons of the BG integrate both "external" inputs from the thalamus and cortex as well as "internal" inputs from other neurons within the BG. Thus, LOS at the output stage of the BG may be attributed either to LOS of the inputs to the system (cortical or thalamic LOS), or to alterations in the internal processing of the information within the BG system. As described in Section "Neuronal Loss of Specificity," LOS of BG neurons can be observed following local inactivation or disinhibition restricted to the BG, without a direct disturbance of the inputs to the system. This suggests that LOS may, in some cases, be primarily driven by dysfunctions of intrinsic BG information processing. In this section we present possible mechanisms of LOS generated or maintained internally by the BG system. Internal processing within the BG system leading to neuronal specificity may be performed either by "intra-nucleus" computation using inhibitory collaterals or interneurons (Figure 3A) or by “inter-nuclei” computation utilizing the integration of projections from multiple upstream nuclei (Figure 3B).

\section{SPECIFICITY RELATED TO INTRA-NUCLEUS PROCESSING}

Specificity generated by computation within a nucleus may be mediated by local inhibitory axon collaterals and/or by inhibitory or modulatory interneurons. The most elaborate local network with such properties can be found in the striatum. The striatum contains a single type of GABAergic projection neurons (medium spiny neurons, MSNs) whose activity is modulated by multiple types of GABAergic, cholinergic, and dopaminergic interneurons, as well as by collateral connections from other MSNs (Calabresi et al., 2000; Tepper et al., 2004; Ibanez-Sandoval et al., 2010). The converging effect of these connections modulates the activity of striatal neurons receiving common excitatory cortical/thalamic inputs (Figure 3A; Wilson, 2007). This modulation may thus generate a selective movement-related activity profile, as neighboring neurons tend to inhibit other MSNs either directly through their collaterals or indirectly via the GABAergic interneurons (Tepper et al., 2004; Wilson, 2007). Disruption of the activity of this intrinsic striatal network could alter the pattern of inhibitory inputs to the neurons and lead to neuronal LOS. Support for this hypothesis can be found in our recent study which showed that local application of the GABA-A antagonist bicuculline in the striatum, which 
A

Intra-nucleus mechanism

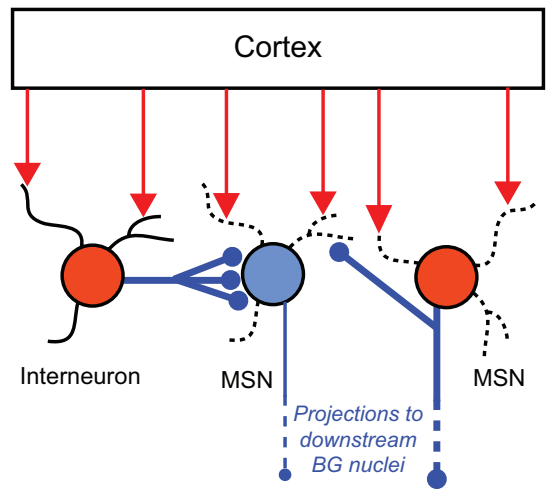

B

Inter-nuclei mechanism

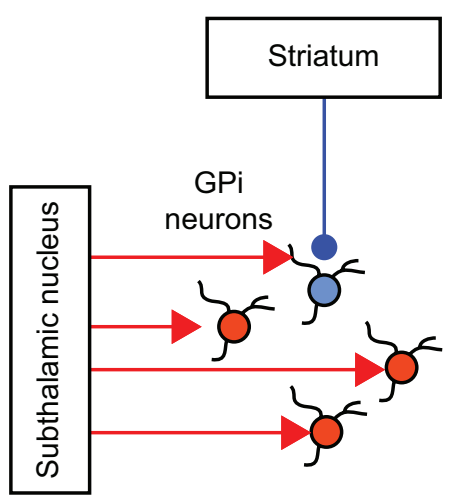

FIGURE 3 | Neural mechanisms underlying neuronal specificity. Schematic illustrations of intra-nucleus (A) and inter-nuclei (B) mechanisms underlying neuronal specificity. Red and blue filled circles represent excited and inhibited neurons, respectively. (A) In the striatum, inhibitory projections from GABAergic interneurons and collaterals from neighboring projection neurons (MSNs) enable selective activation of some MSNs while inhibiting others, in response to common excitatory cortical inputs (Based on: Tepper et al., 2004). (B) In the GPi, the combined effects of spatially focused inhibitory projections from the striatum, and spatially diffused excitatory projections from the subthalamic nucleus enable selective movement-related excitation/inhibition activity patterns (Based on: Mink, 1996). affects only the intrinsic inhibitory network without affecting the excitatory striatal afferents, induces LOS in the striatum and in its downstream targets (Bronfeld et al., 2011).

The significance of lateral processing is reduced in downstream nuclei of the BG system. The GPe does not contain interneurons, but its projection neurons send local axon collaterals (Kita and Kitai, 1994; Sadek et al., 2007). While this suggests that some level of internal processing may be performed within the GPe, the functional significance of these lateral connections has never been examined. The GPi does not contain interneurons either, and moreover, its projection neurons have no significant local axon collaterals (Parent et al., 2001). The STN, which is excitatory in nature, is unsuited for performing internal processing to increase the specificity of its neurons. Thus, the movement-related activity profiles of the pallidal and subthalamic neurons are most likely governed by the input patterns they receive.

\section{SPECIFICITY RELATED TO INTER-NUCLEI PROCESSING}

The GPi integrates excitatory and inhibitory information from multiple BG nuclei, conveyed via several pathways (Albin et al., 1989; DeLong, 1990; Nambu et al., 2002). Inhibitory information from the "direct" pathway is sent from the striatum. The "indirect" and "hyper-direct" pathways involve inhibitory projections from the GPe and excitatory projections from the STN, respectively (Figure 3B). BG output is further modulated by reciprocal connections between the GPe and GPi (Hazrati et al., 1990) and between STN and GPe (Shink et al., 1996), and by dopaminergic innervation (Rommelfanger and Wichmann, 2010). Several models of the BG suggest that the combined effects of inputs from the different pathways can generate "center-surround" patterns of activity (Figure 3B) that lead to neuronal selectivity (Mink, 1996; Nambu et al., 2002; see also "Action Selection" section). Disruption of the normal balance between the different pathways was suggested to underlie many BG-related movement disorders (Crossman et al.,
1988; Albin et al., 1989; DeLong, 1990; Deng et al., 2004; Maia and Frank, 2011) and some evidence suggests it may also be involved in neuronal LOS observed in these disorders.

In the striatum, neurons belonging to the direct or indirect pathways express different subtypes of dopamine receptors (D1 or D2, respectively) that are modulated in opposing manners by dopamine (neuronal excitation or inhibition, respectively; Gerfen et al., 1990). Selective activation of D1 or D2 receptors in the striatum differentially influence the movement-related activity of striatal neurons during performance of a sensorimotor task (Inase et al., 1997), suggesting that this mechanism could contribute to striatal neuronal specificity. We have shown that during the expression of motor tics, LOS was accompanied by an altered increase/decrease ratio of GPi movement-related activity compared to this ratio in intact animals, with phasic rate decreases becoming more frequent (McCairn et al., 2009). This shifted excitation-inhibitions balance suggests that LOS in this case may be associated with an imbalance of the different input pathways to the GPi.

\section{EFFECTS OF LOSS OF SPECIFICITY ON PROPERTIES OF NEURONAL ACTIVITY}

Loss of specificity is defined as an increase in the type and number of behavioral events eliciting similar activity modulations in a neuron, leading to a reduction in the selectivity of the encoding of events. In the extreme case, a complete loss of selectivity results in an equivalent representation of all events. Neuronal LOS may have a major effect on other properties of neurophysiological activity, especially at the population level. In this section we discuss some commonly studied neuronal characteristics and their relation to LOS.

\section{NUMBER OF MOVEMENT-RELATED NEURONS}

A widely accepted indicator of LOS is an increase in the fraction of movement-related neurons out of the whole neuronal population. This is based on the premise that in the normal state many neurons 
which appear to be unrelated to behavior are in fact movementrelated, but have a highly selective activity profile, and are therefore unrelated to the specific combination of kinematic and contextual properties of the applied behavioral paradigm (Figure 4A, left). LOS will increase the number of events that each neuron encodes (Figure 4A, right), encompassing a wider range of motor parameters and behavioral paradigms. Under these circumstances neurons that were previously deemed "unrelated" might now demonstrate movement-related activity. This inevitably leads to an increase in the overall number of neurons whose activity is related to any behavioral task (Figure 4B). This measure of LOS has been widely reported in studies of BG-related disorders (see "Neuronal Loss of Specificity" section and Filion et al., 1988; Lenz et al., 1998; Williams et al., 2005; Baker et al., 2010; Erez et al., 2011), but several confounding factors must be taken into account when evaluating its reliability as an indicator of neuronal LOS.

One limitation is that studies of movement encoding in the BG of human patients suffering from different BG-related disorders can only compare their results to findings obtained from non-human primates. This is due to the fact that recordings from healthy normal people are not available using current technologies. However, the validity of such direct inter-species comparisons is uncertain. In addition, studies of human patients often utilize a variety of methods of motor examination, which may differ from methods used in potentially comparable human and animal studies (Sterio et al., 1994; Taha et al., 1996; Hutchison et al., 2003; Starr et al., 2005; Chang et al., 2007). This may cause a problem as the fraction of movement-related neurons has been shown to be highly dependent on the exact features of the performed motor task (DeLong, 1973; Mink and Thach, 1987), and might even be affected by its cognitive demands and by the subject's emotional state (Alexander and Crutcher, 1990b; Brotchie et al., 1991b; Arkadir et al., 2004). This implies that differences in task and setup should be taken into account when evaluating the fraction of movement-related neurons observed in different studies, and optimally only data obtained from experiments in which a similar motor task was used should be compared.

Another limitation arises from the fact that the relative number of movement-related neurons varies significantly between different functional territories within the same nucleus. For example, the prevalence of movement-related neurons may seem larger when recording at the motor compared to the associative functional territories (DeLong, 1971; Alexander and DeLong, 1985; Wichmann
A Normal state (Specific encoding)

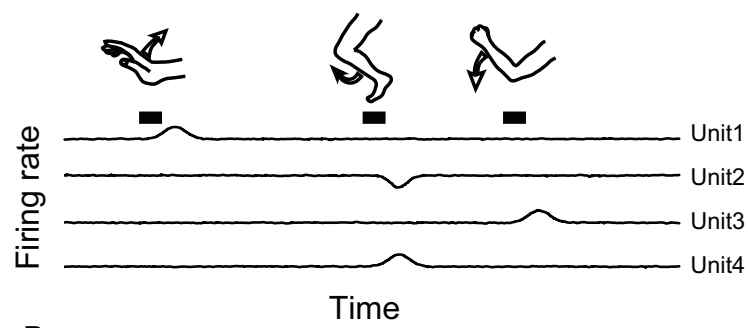

B

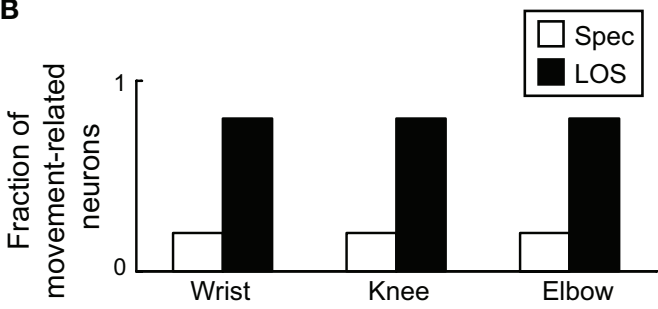

C (i)

(ii)
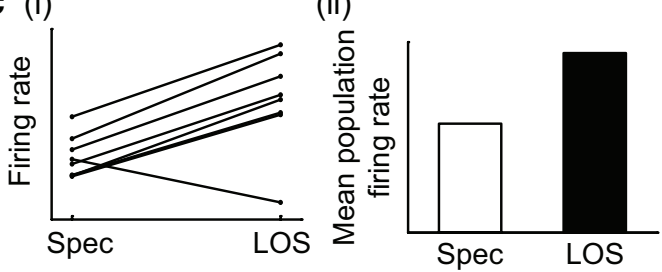

FIGURE 4 | Effect of loss of specificity on properties of neuronal activity. (A) Illustration of firing rate fluctuations of multiple neurons, depicting rate modulations related to different movements, in a neuronal population for which rate increases are the predominant pattern of movement-related activity. Left: Specific encoding, each neuron modulates its firing rate in response to a single type of movement. Right: Loss of specificity (LOS); each neuron displays similar movement-related rate modulations in response to a larger range of movements. (B) Following LOS, the fraction of movement-related neurons is increased. (C) The number of movements eliciting rate modulations in each
Abnormal state (Non-specific encoding)

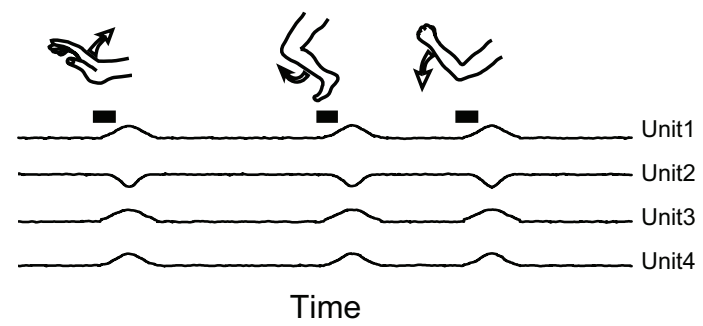

D
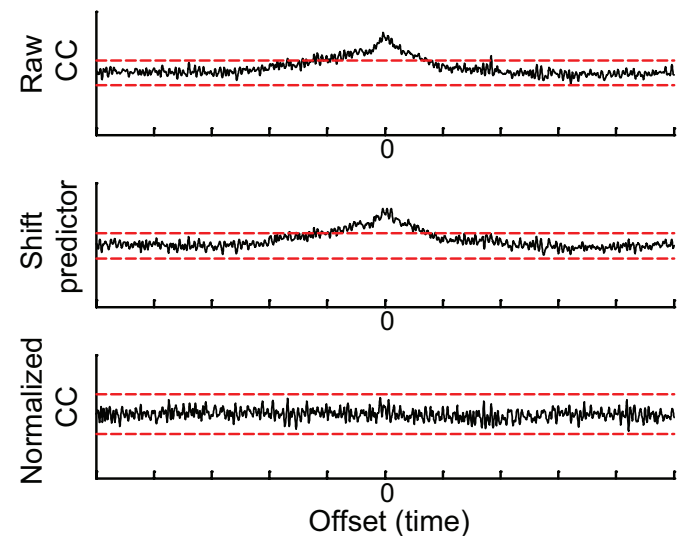

neuron increases, resulting in an increased effect of movements on the overall average firing rate of each neuron (i). For a population in which most neurons have a dominant non-specific response pattern (such as firing rate increase), LOS has an effect on the overall average firing rate of the population (ii). (D) Non-specific encoding of movements generates correlations between pairs of neurons (top panel). These correlations represent only the common rate modulations attributed to the commonly encoded movements, and following subtraction of these effects (middle panel, the shift predictor), the normalized correlation function shows no correlation between the neurons (bottom panel) 
et al., 1994; Jaeger et al., 1995). As many studies of human patients often specifically target the motor territory of the BG they may be inherently biased toward a higher prevalence of movement-related neurons. Furthermore, considering that in the STN and GP the distance between one territory or another may be only $1-2 \mathrm{~mm}$ with no clear physiological borders between territories (DeLong, 1971; Wichmann et al., 1994), the sampling distribution of two neuronal populations might easily be inadvertently skewed toward one of the functional domains and thus influence the fraction of movement-related neurons. Even within the motor territory, the somatotopic organization of the BG means that the number of recorded neurons might be affected by the interaction between recording location and the body part involved in the motor task.

These confounding features might partially account for the substantial differences in the fraction of movement-related neurons reported in different studies, especially experiments comparing results from human patients and non-human primates (Filion et al., 1988; Taha et al., 1996; Williams et al., 2005; Leblois et al., 2006; Chang et al., 2007; Guehl et al., 2009). Despite the aforementioned limitations, the fraction of movement-related neurons should not be excluded as a measure of LOS. When comparing normal and abnormal states of subjects performing the same motor task and controlling for the location of recorded neurons, it may serve as a robust measure of LOS.

\section{RATE CHANGES}

In some circumstances, LOS may lead to an apparent global change in the overall activation level of the neurons. Consider for example a neuronal population in which each neuron responds selectively to different behavioral events, but event-related neuronal rate modulations are always or predominantly of the same type (either firing rate increases or decreases). In the normal state, neuronal specificity will lead to rate modulations in only a small fraction of the neurons at any given time, resulting in a minor effect on the overall firing rate of the population. However, LOS will lead to more neurons displaying activity modulations related to any behavioral event, and their combined effect may result in an apparent change in the mean firing rate of the population, whose direction (increase or decrease of the rate) depends on the predominant modulation of the neurons (Figure 4C). This description could be applicable to both the striatum, in which all projection neurons increase their firing rate in relation to preferred events (DeLong, 1973), and to the globus pallidus, in which firing rate increases are predominant in the normal state (Mitchell et al., 1987; Mink and Thach, 1991b; Turner and Anderson, 1997) and decreases in some abnormal states (McCairn et al., 2009).

However, global firing rate changes are certainly not always related to LOS. First, LOS might only account for firing rate changes observed in behaving subjects, and not in subjects during periods of passive immobility. Second, global rate changes are often attributed to tonic changes in activation, rather than phasic event-related changes. Examination of firing patterns and rate modulations over time could help differentiate between global and event-related rate modulations. Thus, the possibility of neuronal LOS should be addressed in cases of observed population rate changes in moving/behaving subjects.

\section{CORRELATED ACTIVITY}

Another potential epiphenomenon of neuronal LOS is an increase in the level of temporally correlated activity across a neuronal population. The most widely used measure of correlated activity is the cross-correlation function, which describes the temporal correlation between spiking activities of pairs of neurons (Perkel et al., 1967). Whenever two neurons encode the same behavioral event, they will both phasically change their activity around occurrences of that event, resulting in periods of temporally related rate modulations. For a population of neurons with highly selective movement-related activity profiles, commonly encoded events will be rare and thus the firing rate of each neuron will fluctuate in a temporally independent way (Figure 4A). As neurons become less specific, they are more likely to encode the same events, and thus display more periods of common rate modulations. In this case, a change in the spiking probability of one neuron, resulting from the commonly encoded behavioral event, will be accompanied by a change in spiking probability of other neurons encoding the same event. As a result, the cross-correlation function of the neurons will be more likely to demonstrate a significant correlation between them (Figure 4D; Nevet et al., 2007). This is regarded as an "artificial" correlation, as it may occur despite the lack of a direct neural pathway connecting the neurons (Stevens and Gerstein, 1976).

An increase in the level of correlated activity in the BG was reported in BG-related movement disorders (Raz et al., 2000). The LOS that is also observed in these disorders stresses the importance of controlling for commonly encoded events when evaluating the true level of correlations in the system. Several statistical methods have been developed for removing the effects of commonly encoded events from cross-correlation functions, such as the shift predictor (Figure 4D; Moore et al., 1966; Stevens and Gerstein, 1976), joint peri-event time histograms (Gochin et al., 1990), and signal and noise correlations (Gawne and Richmond, 1993).

However, while LOS might affect the level of correlation, there are several parameters mediating its effect. A recent study emphasized that the likelihood of correlation modulation by commonly encoded events depends on the number of events and the magnitude of the event-related rate modulations (Nevet et al., 2007). This implies that a lack of correlation cannot be used to exclude the possibility of LOS in the system. Additionally, there are other factors which may contribute to an increased level of correlation unrelated to LOS, such as global brain activation states or population wide oscillatory activity patterns (Nini et al., 1995; Urbain et al., 2000).

\section{THEORETICAL MODELS OF BG FUNCTION AND DYSFUNCTION}

Theoretical models have tried to conceptualize the accumulating data of the BG system into a unified model explaining its role in normal behavior and in different pathological states (Figure 5). The early "box and arrow" model relied primarily on the anatomical connectivity of the BG, and described different normal and pathological states as deriving from global changes in the overall firing rate in different nuclei within the pathway. Later models addressed more detailed spatial and temporal patterns of the BG output, and how changes in these patterns may lead to abnormal states. This section reviews these models and the extent to which they address the phenomena of LOS in different BG-related disorders. 


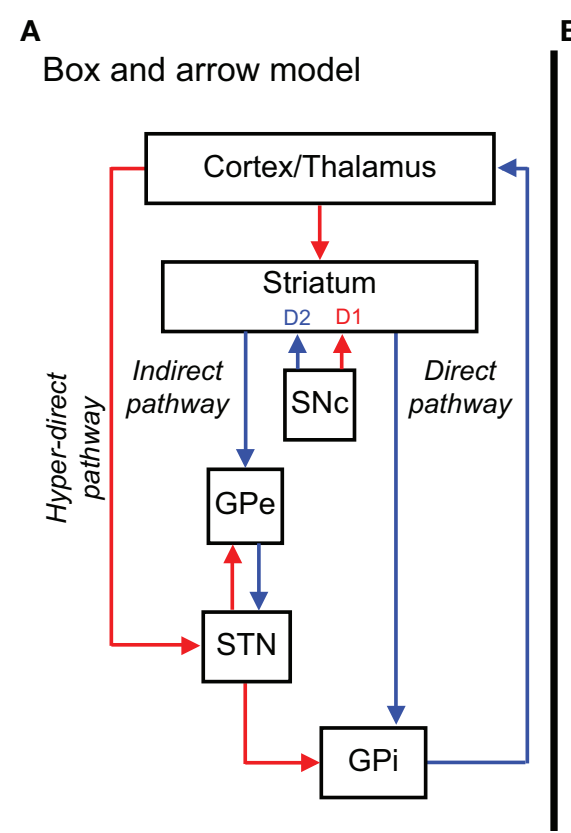

B

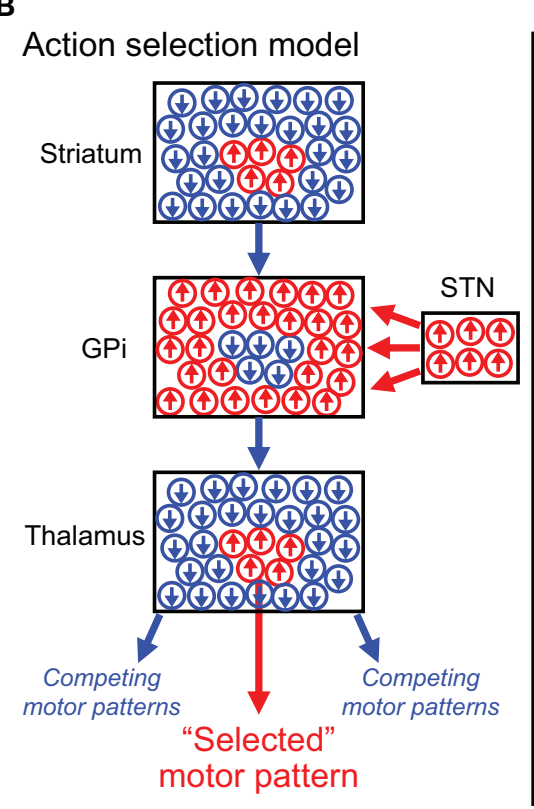

C

Reinforcement driven
dimesionality reduction model

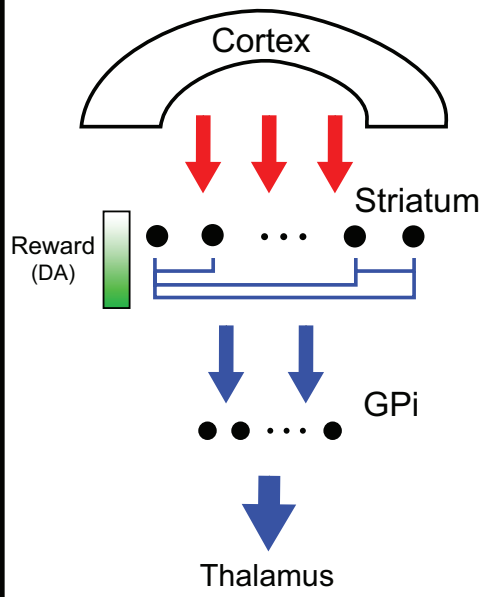

FIGURE 5 |Theoretical models of the basal-ganglia. In all panels blue and red arrows indicate inhibitory and excitatory effects, respectively. (A) Schematic representation of the BG circuitry, according to the "box and arrow" model. (Based on: Albin et al., 1989; DeLong, 1990). (B) Illustration of BG "action selection process": integration of excitatory and inhibitory pathways through the BG lead to focused excitation and diffused "surround" inhibition of thalamic neurons, thereby selecting the desired motor pattern while inhibiting potentially competing motor patterns (Based on: Mink, 1996). (C) Structure of the cortico-BG neural network according to the "reinforcement driven dimensionality reduction" model. Information from multiple cortical regions is integrated by lateral inhibitory connections within the striatum and feed-forward projections from the striatum to the GPi. A reward signal is provided via dopaminergic (DA) projections, and used to modulate the relative significance of different input dimensions (Based on: Bar-Gad et al., 2000).

\section{THE BOX AND ARROW MODEL}

The "box and arrow" model described the BG as part of a feedback loop influencing the level of cortical excitability (Albin et al., 1989; DeLong, 1990). Each BG nucleus was described as a single unit ("box") whose activity exerts either excitation or inhibition (positive or negative "arrows") on its downstream targets (Figure 5A). An increase or a decrease in the level of activity of the BG output structure (the GPi for most movement-related information) was considered to inhibit or facilitate (disinhibit) cortical activity, respectively, via the thalamus.

Neuronal specificity is not accounted for at all by this model, as it treats each nucleus as a single entity, while disregarding the complex and unique movement-related firing patterns of different neurons within the same nucleus. Thus, the model assumes that specificity is not a significant feature of either the normal or pathological states, since multiple neurons are expected to be activated simultaneously and in a similar manner as an underlying definition of the model. Accordingly, LOS cannot be explained in the context of the box and arrow model.

\section{ACTION SELECTION}

A model that tried to account for the dynamic intra-nucleus and inter-nuclei effects of BG neuronal activity, and offer a networklevel model of the BG was the "action selection" model. This model depicted the BG as instructing the cortex on which action should be selected for performance out of a multitude of potential actions (Mink, 1996). According to this model, each possible motor pattern (action) is represented by a small group of neurons in the BG output structure. Selective inhibition of one such group of neurons, while facilitating the activity of all the others, leads to facilitation of the cortical neurons encoding the selected action while inhibiting other competing actions (Figure 5B; Chevalier and Deniau, 1990).

The selection process was proposed to be mediated by intranucleus connections, inter-nuclei connections, or a combination of both (see also "Mechanisms Underlying Neuronal Specificity"). Intra-nucleus models derived originally from the lateral inhibitory connections between projection neurons in the striatum, which suggested that activation of one neuron can lead to inhibition of others (Wickens, 1993). It was later suggested that the same outcome could also be achieved by the local striatal network of inhibitory GABAergic interneurons (Koos and Tepper, 1999). According to inter-nuclei models, the selection process utilizes the excitatory and inhibitory projections reaching the GPi via different BG pathways (Mink, 1996; Nambu et al., 2002). These models rely on the different spatial distribution of afferents originating from the different pathways. Thus, the direct pathway from the striatum generates focused inhibition in a subpopulation of GPi neurons, while projections from the STN and GPe (through the hyper-direct and indirect pathways) exert diffuse GPi excitation. The combined effect of inputs from these pathways generates a focused center of GPi inhibition surrounded by diffused excitation, forming the "Mexican hat" activation pattern (Figure 5B).

Neuronal specificity in the normal BG and the observed pallidal movement-related activity may be explained in terms of the action selection model. The underlying assumption of the model, 
that each small neuronal group in the GPi encodes a particular motor pattern, entails selective activity profiles of these neurons. According to the model, the pallidal neurons whose activity is related to a particular motor task are the neurons encoding for the task-specific motor patterns, and any potentially competing patterns. These two neuronal populations should display opposing patterns of movement-related rate modulations, which account for the observed movement-related rate increases and decreases (DeLong, 1971). The smaller subpopulation of neurons displaying movement-related inhibition is composed of neurons whose activity facilitates the selection of the desired appropriate motor pattern. The larger population of neurons excited around movement-time includes neurons whose movement-related activity generates increased inhibition (suppression) of the competing motor patterns (Mink, 1996).

According to the action selection model, LOS may be explained as a failure to select a single motor pattern, and/or by a failure to inhibit competing patterns. However, certain predictions of the action selection model regarding patterns of neuronal specificity in BG-related movement disorders have recently been contested by experimental data. Action selection models suggest that hypokinetic symptoms of $\mathrm{PD}$ are related to an inability to remove excessive inhibition from the cortical neurons related to the desired motor pattern (Mink, 1996). However, the GPi neuronal population in PD still displays a mixture of movement-related firing rate increases and decreases, in proportions comparable to the normal state, suggesting that the potential for cortical disinhibition is maintained (Bergman et al., 1994; Taha et al., 1996; Williams et al., 2005). An action selection model of motor tics hypothesized that tics are associated with an abnormal inhibition of a restricted subset of pallidal neurons, whose activity encodes the tic-related motor pattern (Mink, 2001; Albin and Mink, 2006). However, our results from a non-human primate model of motor tics indicated that a vast majority, rather than a restricted subpopulation of GPi neurons were inhibited around tic-times (Figure 2; McCairn et al., 2009). According to the action selection hypothesis such an activity pattern should have led to the simultaneous activation of multiple motor patterns. Instead, the only expressed movement was the localized motor tic (McCairn et al., 2009; Bronfeld et al., 2011).

\section{REINFORCEMENT DRIVEN DIMENSIONALITY REDUCTION}

The reinforcement driven dimensionality reduction (RDDR) model provides a conceptual representation of the BG and their role in neural information processing within the central nervous system (Bar-Gad et al., 2003). The BG are depicted as receiving high-dimensionality input and generating a compressed lowerdimensionality representation of it, while maintaining maximal information regarding the original input (Figure $5 \mathrm{C}$ ). Thus, the BG serve as an integrator of the vast information available to the organism which is represented by the distributed activity of multiple brain regions. This information is integrated and compressed within the BG and conveyed to other brain structures (such as the frontal cortex, or subcortical structures), which can use it to optimally direct the organism's behavior. The RDDR model differs from the action selection model by the type of information conveyed by the BG and the way it is represented. In the RDDR model, the decision of which action should be performed is not taken by the BG, but rather at the level of their downstream targets (e.g., the frontal cortex). The activity of each pallidal neuron does not represent one specific motor pattern. Instead, specific combinations of inputs, representing different states or properties of the organism, the behavior and the environment, are represented by the combined activity of pallidal neurons. In the RDDR model, the role of reinforcement is to modulate the relative "importance" of the different input dimensions. Reward-related dimensions receive more detailed representations, while unrewarded dimensions are poorly represented in the output of the BG.

Neuronal specificity is directly derived from maximizing the amount of transferred information in the RDDR model. The activity of each pallidal neuron represents a unique subspace of inputs; for example, inputs relevant to a specific motor task. Several neurons can be related to the same task (encode a similar set of inputs) as long as their activity encodes different features of it. This selective representation increases the efficiency of the network by enabling a small number of neurons to transfer larger (maximal) amounts of information (Bar-Gad et al., 2000). The RDDR model can also account for the importance of LOS as a key feature of BG-related disorders. LOS reduces the information capacity of each neuron, as it uniformly encodes many different input states (BarGad et al., 2000). This degrades the overall amount of information conveyed by the BG, making its output signal unreliable for accurate reconstruction of the original input space. The degraded information conveyed to the cortical neurons may lead to the choice of inappropriate courses of action, which will manifest as abnormal behavioral patterns.

\section{MULTIPLE FUNCTIONS}

While different theoretical models disagree on the very basic question of what is the role of the BG signal, the complex and multi-functional nature of the system suggests that it may serve multiple roles. For example, BG event-related activity displays a wide temporal distribution relative to the observed event. In the motor domain, some movement-related activity can be detected well before movement onset while some occurs after movement initiation (Georgopoulos et al., 1983; Hikosaka and Wurtz, 1983; Brotchie et al., 1991a; Gardiner and Nelson, 1992; Jaeger et al., 1995; Turner and Anderson, 1997). These temporally distinct signals may contribute to different computational processes performed by the BG system. These may include activation of motor planning or selection mechanisms mediated by early BG signals and sensorimotor feedback or learning mechanisms mediated by the late signals (Turner and Desmurget, 2010). Furthermore, it is possible that signals processed within the limbic, cognitive, or motor loops going through the BG (Alexander et al., 1986; Haber et al., 2000) may serve separate roles when conveyed to their downstream targets. If this is the case than perhaps any one theoretical model captures only one aspect of BG functionality, and multiple models may co-exist as attaining to different computational tasks performed by the BG system (Joel and Weiner, 1994; Maia and Frank, 2011).

One implication of this hypothesis is that different functional pathways may be differentially affected in BG-related disorders. If this is the case we might expect to observe unique patterns of LOS in different pathological conditions. This may be reflected by LOS 
occurring in some aspects of a behavior but not in others. For example, we might observe LOS of the motor responses to a behavior but not to the cognitive aspects of it, or vice versa. Such selective dysfunction may also be reflected by changes in the temporal distribution of event-related neuronal activity, which was reported in one study of MPTP-treated monkeys (Leblois et al., 2006).

\section{ROLE OF BASAL-GANGLIA LOSS OF SPECIFICITY}

Loss of neuronal specificity is a feature of the abnormal neuronal activity associated with many BG-related movement disorders. Its prevalence suggests that it may be a key factor of the BG pathophysiology leading to abnormal motor or behavioral symptoms. However, since LOS is a common feature of multiple hypokinetic and hyperkinetic disorders, what might account for their unique and diverse clinical manifestations? Based on existing data, we speculate that different symptoms may be related to the location and type of BG dysfunction and to the level of dopaminergic modulation.

Computational models of the cortico-BG system often regard the $B G$ as a multilayer feed-forward neural network, in which each layer contains different patterns of both external and internal connectivity (Bar-Gad et al., 2003; Gurney et al., 2004). Selective changes to any one of these parameters were shown to have different effects on the network output, depending on their type and location (Prescott et al., 2006). While no direct models for LOS were examined, arguably this may apply to network selectivity profiles as well. Thus, while the loss of selectivity may be a common feature, the exact nature or pattern of information that is lost following its processing within a dysfunctional BG system may account for the nature of the observed motor or behavioral abnormalities.

Another parameter that may affect the pattern of BG output is dopamine, which is often regarded as a reinforcement signal indicating the relative saliency or importance of various inputs (Schultz, 2007; Joshua et al., 2009a; Zhang et al., 2009). Anatomical and physiological evidence suggest that the dopaminergic signal in the striatum is largely diffused rather than spatially selective, affecting multiple synaptic connections simultaneously (Schultz, 1998; Moss and Bolam, 2008; Joshua et al., 2009b). Thus, the dopaminergic signal by itself is probably not responsible for the specificity observed in BG neurons. Rather, fluctuations in the levels of dopamine in

\section{REFERENCES}

Agid, Y.(1991). Parkinson's disease: pathophysiology. Lancet 337, 1321-1324.

Albin, R. L., and Mink, J. W. (2006). Recent advances in Tourette syndrome research. Trends Neurosci. 29, 175-182.

Albin, R. L., Young, A. B., and Penney, J. B. (1989). The functional anatomy of basal ganglia disorders. Trends Neurosci. 12, 366-375.

Alexander, G. E., and Crutcher, M. D. (1990a). Functional architecture of basal ganglia circuits: neural substrates of parallel processing. Trends Neurosci. 13, 266-271.

Alexander, G. E., and Crutcher, M. D. (1990b). Neural representations of the target (goal) of visually guided arm movements in three motor

the system can induce dynamic changes in network connectivity by weakening or strengthening synaptic connections (Wickens et al., 1996; Kerr and Wickens, 2001). These internal connections within the BG system may in turn be responsible for the observed patterns of neuronal specificity (see section "Mechanisms Underlying Neuronal Specificity"). In the normal state, fluctuations in dopamine levels are expected to be related to events in the organism's environment and thus lead to adaptive changes in the BG network and in the organism's behavior. In many BG-related disorders there is a dysregulation of the dopaminergic system (Hassler, 1939; Hesse et al., 2005; Gil and Rego, 2008; Steeves and Fox, 2008; Wichmann, 2008; Wong et al., 2008; Tripp and Wickens, 2009), which may result both in a breakdown of the relation between dopamine levels and the relative saliency or reward value of the inputs to the system, and in maladaptive changes in the BG network connectivity. This could lead to both a loss of specificity of the neuronal encoding and to degradation of the information conveyed by the BG and thus induce the input-inappropriate expression of abnormal movements and behaviors (Bar-Gad et al., 2000; Gurney et al., 2001).

\section{SUMMARY}

Neuronal specificity emerges as a key feature of information processing in the normal BG. BG specificity has a multi-dimensional nature, with neurons showing selective activity patterns related to different combinations of motor, associative, and limbic properties of state and behavior. This highlights the special role of the BG in integrating and processing information from multiple modalities to influence behavior. Accordingly, loss of specificity of neuronal encoding is a main feature in BG dysfunction. Evidence for LOS have been observed in many BG-related disorders, both in human patients and in animal models of the disorder. The appearance of LOS following localized BG dysfunction with intact patterns of input to the system, suggests that LOS is primarily a direct result of changes in the internal processing within the BG. This prevalence of LOS implies that neuronal specificity reflects a basic computational role of the $\mathrm{BG}$, and its loss may be the major underlying pathology driving the appearance of abnormal motor symptoms. Future computational and theoretical models of BG function should address its multi-modality neuronal specificity and explore changes in specificity related to different BG dysfunctions.

Anderson, V. C., Burchiel, K. J., Hogarth, P., Favre, J., and Hammerstad, J. P. (2005). Pallidal vs subthalamic nucleus deep brain stimulation in Parkinson disease. Arch. Neurol. 62, 554-560.

Arkadir, D., Morris, G., Vaadia, E., and Bergman, H. (2004). Independent coding of movement direction and reward prediction by single pallidal neurons. J. Neurosci. 24, 10047-10056.

Baker, K. B., Lee, J. Y., Mavinkurve, G., Russo, G., Walter, B., DeLong, M. R., Bakay, R. A., and Vitek, J. L. (2010). Somatotopic organization in the internal segment of the globus pallidus in Parkinson's disease. Exp. Neurol. 222, 219-225.

Bar-Gad, I., Havazelet-Heimer, G., Goldberg, J. A., Ruppin, E., and
Bergman, H. (2000). Reinforcementdriven dimensionality reduction - a model for information processing in the basal ganglia. J. Basic Clin. Physiol. Pharmacol. 11, 305-320.

Bar-Gad, I., Morris, G., and Bergman, H. (2003). Information processing, dimensionality reduction and reinforcement learning in the basal ganglia. Prog. Neurobiol. 71, 439-473.

Bara-Jimenez, W., Catalan, M. J., Hallett, M., and Gerloff, C. (1998). Abnormal somatosensory homunculus in dystonia of the hand. Ann. Neurol. 44, 828-831.

Bergman, H., Wichmann, T., Karmon, B., and DeLong, M. R. (1994). The primate subthalamic nucleus. II. Neuronal activity in the MPTP model 
of parkinsonism. J. Neurophysiol. 72, 507-520.

Bezard, E., Brotchie, J. M., and Gross, C. E. (2001). Pathophysiology of levodopa-induced dyskinesia: potential for new therapies. Nat. Rev. Neurosci. 2, 577-588.

Boraud, T., Bezard, E., Bioulac, B., and Gross, C. E. (2000). Ratio of inhibitedto-activated pallidal neurons decreases dramatically during passive limb movement in the MPTP-treated monkey. J. Neurophysiol. 83, 1760-1763.

Bronfeld, M., Belelovsky, K., and Bar-Gad, I. (2011). Spatial and temporal properties of tic-related neuronal activity in the cortico-basal ganglia loop. J. Neurosci. (in press).

Bronfeld, M., Belelovsky, K., Erez, Y., Bugaysen, J., Korngreen, A., and BarGad, I. (2010). Bicuculline induced chorea manifests in focal rather than globalized abnormalities in the activation of the external and internal globus pallidus. J. Neurophysiol. 104, 3261-3275.

Brotchie, P., Iansek, R., and Horne, M. K. (1991a). Motor function of the monkey globus pallidus. 1. Neuronal discharge and parameters of movement. Brain 114(Pt 4), 1667-1683.

Brotchie, P., Iansek, R., and Horne, M. K. (1991b). Motor function of the monkey globus pallidus. 2. Cognitive aspects of movement and phasic neuronal activity. Brain 114(Pt 4), 1685-1702.

Burns, R. S., Chiueh, C. C., Markey, S. P., Ebert, M. H., Jacobowitz, D. M., and Kopin, I. J. (1983). A primate model of parkinsonism: selective destruction of dopaminergic neurons in the pars compacta of the substantia nigra by $N$-methyl-4-phenyl-1,2,3,6tetrahydropyridine. Proc. Natl. Acad. Sci. U.S.A. 80, 4546-4550.

Calabresi, P., Centonze, D., Gubellini, P., Pisani, A., and Bernardi, G. (2000). Acetylcholine-mediated modulation of striatal function. Trends Neurosci. $23,120-126$.

Carpenter, M. B., Nakano, K., and Kim, R. (1976). Nigrothalamic projections in the monkey demonstrated by autoradiographic technics. J. Comp. Neurol. 165, 401-415.

Chang, E. F., Turner, R. S., Ostrem, J. L., Davis, V. R., and Starr, P. A. (2007). Neuronal responses to passive movement in the globus pallidus internus in primary dystonia. J. Neurophysiol. 98, 3696-3707.

Chevalier, G., and Deniau, J. M. (1990). Disinhibition as a basic process in the expression of striatal functions. Trends Neurosci. 13, 277-280.

Coubes, P., Roubertie, A., Vayssiere, N., Hemm, S., and Echenne, B. (2000). Treatment of DYT1-generalised dystonia by stimulation of the internal globus pallidus. Lancet 355 , 2220-2221.

Crossman, A. R. (1987). Primate models of dyskinesia: the experimental approach to the study of basal gangliarelated involuntary movement disorders. Neuroscience 21, 1-40.

Crossman, A. R., Mitchell, I. J., Sambrook, M. A., and Jackson, A. (1988). Chorea and myoclonus in the monkey induced by gamma-aminobutyric acid antagonism in the lentiform complex. The site of drug action and a hypothesis for the neural mechanisms of chorea. Brain 111(Pt 5), 1211-1233.

Crutcher, M. D., and DeLong, M. R. (1984). Single cell studies of the primate putamen. II. Relations to direction of movement and pattern of muscular activity. Exp. Brain Res. 53, 244-258.

Del, S. F., and Albanese, A. (2008). Levodopa-induced dyskinesias and their management. J. Neurol. 255(Suppl. 4), 32-41.

Delmaire, C., Krainik, A., Tezenas du, M. S., Gerardin, E., Meunier, S., Mangin, J. F., Sangla, S., Garnero, L., Vidailhet, M., and Lehericy, S. (2005). Disorganized somatotopy in the putamen of patients with focal hand dystonia. Neurology 64, 1391-1396.

DeLong, M. R. (1971). Activity of pallidal neurons during movement. $J$. Neurophysiol. 34, 414-427.

DeLong, M. R. (1972). Activity of basal ganglia neurons during movement. Brain Res. 40, 127-135.

DeLong, M. R. (1973). Putamen: activity of single units during slow and rapid arm movements. Science 179, 1240-1242.

DeLong, M. R. (1990). Primate models of movement disorders of basal ganglia origin. Trends Neurosci. 13, 281-285.

DeLong, M. R., Crutcher, M. D., and Georgopoulos, A. P. (1985). Primate globus pallidus and subthalamic nucleus: functional organization. $J$. Neurophysiol. 53, 530-543.

Deng, Y. P., Albin, R. L., Penney, J. B., Young, A. B., Anderson, K. D., and Reiner, A. (2004). Differential loss of striatal projection systems in Huntington's disease: a quantitative immunohistochemical study. J. Chem. Neuroanat. 27, 143-164.

Desmurget, M., and Turner, R. S. (2008). Testing basal ganglia motor functions through reversible inactivations in the posterior internal globus pallidus. J. Neurophysiol. 99, 1057-1076.

di Michele, F., Prichep, L., John, E. R., and Chabot, R.J. (2005). The neurophysiology of attention-deficit/hyperactivity disorder. Int. J. Psychophysiol. 58, 81-93. Erez, Y., Tischler, H., Belelovsky, K., and Bar-Gad, I. (2011). Dispersed activity during passive movement in the globus pallidus of the 1-methyl4-phenyl-1,2,3,6-tetrahydropyridine (MPTP)-treated primate. PLoS ONE 6, e16293. doi: 10.1371/journal. pone. 0016293

Fahn, S., and Eldridge, R. (1976). Definition of dystonia and classification of the dystonic states. Adv. Neurol. $14,1-5$.

Filion, M., Tremblay, L., and Bedard, P. J. (1988). Abnormal influences of passive limb movement on the activity of globus pallidus neurons in parkinsonian monkeys. Brain Res. 444, 165-176.

Gardiner, T. W., and Nelson, R. J. (1992). Striatal neuronal activity during the initiation and execution of hand movements made in response to visual and vibratory cues. Exp. Brain Res. 92, 15-26.

Gawne, T. J., and Richmond, B. J. (1993). How independent are the messages carried by adjacent inferior temporal cortical neurons? J. Neurosci. 13, 2758-2771.

Georgopoulos, A. P., DeLong, M. R., and Crutcher, M. D. (1983). Relations between parameters of step-tracking movements and single cell discharge in the globus pallidus and subthalamic nucleus of the behaving monkey. $J$. Neurosci. 3, 1586-1598.

Gerfen, C. R., Engber, T. M., Mahan, L. C., Susel, Z., Chase, T. N., Monsma, F. J. Jr., and Sibley, D. R. (1990). D1 and D2 dopamine receptor-regulated gene expression of striatonigral and striatopallidal neurons. Science 250, 1429-1432.

Gil, J. M., and Rego, A. C. (2008). Mechanisms of neurodegeneration in Huntington's disease. Eur. J. Neurosci. 27, 2803-2820.

Glass, M., Dragunow, M., and Faull, R. L. (2000). The pattern of neurodegeneration in Huntington's disease: a comparative study of cannabinoid, dopamine, adenosine and GABA(A) receptor alterations in the human basal ganglia in Huntington's disease. Neuroscience 97, 505-519.

Gochin, P. M., Gerstein, G. L., and Kaltenbach, J. A. (1990). Dynamic temporal properties of effective connections in rat dorsal cochlear nucleus. Brain Res. 510, 195-202.

Grabli, D., McCairn, K., Hirsch, E. C., Agid, Y., Feger, J., Francois, C., and Tremblay, L. (2004). Behavioural disorders induced by external globus pallidus dysfunction in primates: I. Behavioural study. Brain 127, 2039-2054.

Graybiel, A. M., and Rauch, S. L. (2000). Toward a neurobiology of obsessivecompulsive disorder. Neuron 28, 343-347.
Guehl, D., Cuny, E., Ghorayeb, I., Michelet, T., Bioulac, B., and Burbaud, P. (2009). Primate models of dystonia. Prog. Neurobiol. 87, 118-131.

Gurney, K., Prescott, T. J., and Redgrave, P. (2001). A computational model of action selection in the basal ganglia. II. Analysis and simulation of behaviour. Biol. Cybern. 84, 411-423.

Gurney, K., Prescott, T. J., Wickens, J. R., and Redgrave, P. (2004). Computational models of the basal ganglia: from robots to membranes. Trends Neurosci. 27, 453-459.

Haber, S. N., Fudge, J. L., and McFarland, N.R. (2000). Striatonigrostriatal pathways in primates form an ascending spiral from the shell to the dorsolateral striatum. J. Neurosci. 20, 2369-2382.

Hamada, I., and DeLong, M. R. (1992). Excitotoxic acid lesions of the primate subthalamic nucleus result in transient dyskinesias of the contralateral limbs. J. Neurophysiol. 68, 1850-1858.

Hassler, R. (1939). Zurpathologischenanatomie des senilen und des parkinsonistischen tremor. J. Psychol. Neurol. 43, 193-230.

Hazrati, L. N., Parent, A., Mitchell, S., and Haber, S. N. (1990). Evidence for interconnections between the two segments of the globus pallidus in primates: a PHA-L anterograde tracing study. Brain Res. 533, 171-175.

Hesse, S., Muller, U., Lincke, T., Barthel, H., Villmann, T., Angermeyer, M. C., Sabri, O., and Stengler-Wenzke, K. (2005). Serotonin and dopamine transporter imaging in patients with obsessive-compulsive disorder. Psychiatry Res. 140, 63-72.

Hikosaka, O., and Wurtz, R. H. (1983). Visual and oculomotor functions of monkey substantia nigra pars reticulata. III. Memory-contingent visual and saccade responses. J. Neurophysiol. 49, 1268-1284.

Hornykiewicz, O. (1966). Dopamine (3-hydroxytyramine) and brain function. Pharmacol. Rev. 18, 925-964.

Hutchison, W. D., Lang, A. E., Dostrovsky, J. O., and Lozano, A. M. (2003). Pallidal neuronal activity: implications for models of dystonia. Ann. Neurol. 53, 480-488.

Ibanez-Sandoval, O., Tecuapetla, F., Unal, B., Shah, F., Koos, T., and Tepper, J. M. (2010). Electrophysiological and morphological characteristics and synaptic connectivity of tyrosine hydroxylase-expressing neurons in adult mouse striatum. J. Neurosci. 30, 6999-7016.

Inase, M., Li, B. M., and Tanji, J. (1997). Dopaminergic modulation of neuronal activity in the monkey putamen through D1 and D2 receptors during a delayed Go/Nogo task. Exp. Brain Res. $117,207-218$. 
Jaeger, D., Gilman, S., and Aldridge, J. W. (1995). Neuronal-activity in the striatum and pallidum of primates related to the execution of externally cued reaching movements. Brain Res. 694, 111-127.

Jenner, P. (2003). The contribution of the MPTP-treated primate model to the development of new treatment strategies for Parkinson's disease. Parkinsonism Relat. Disord. 9, 131-137.

Joel, D. (2001). Open interconnected model of basal ganglia-thalamocortical circuitry and its relevance to the clinical syndrome of Huntington's disease. Mov. Disord. 16, 407-423.

Joel, D., and Weiner, I. (1994). The organization of the basal ganglia-thalamocortical circuits: open interconnected rather than closed segregated. Neuroscience 63, 363-379.

Joshua, M., Adler, A., and Bergman, H. (2009a). The dynamics of dopamine in control of motor behavior. Curr. Opin. Neurobiol. 19, 615-620.

Joshua, M., Adler, A., Prut, Y., Vaadia, E., Wickens, J. R., and Bergman, H. (2009b). Synchronization of midbrain dopaminergic neurons is enhanced by rewarding events. Neuron 62, 695-704.

Kerr, J. N., and Wickens, J. R. (2001). Dopamine D-1/D-5 receptor activation is required for long-term potentiation in the rat neostriatum in vitro. J. Neurophysiol. 85, 117-124.

Kim, R., Nakano, K., Jayaraman, A., and Carpenter, M. B. (1976). Projections of the globus pallidus and adjacent structures: an autoradiographic study in the monkey. J. Comp. Neurol. 169, 263-290.

Kita, H., and Kitai, S. T. (1994). The morphology of globus pallidus projection neurons in the rat: an intracellular staining study. Brain Res. 636, 308-319.

Koos, T., and Tepper, J. M. (1999). Inhibitory control of neostriatal projection neurons by GABAergic interneurons. Nat. Neurosci. 2, 467-472.

Kurlan, R. (2004). “Tourette’s syndrome," in Movement Disorders: Neurologic Principles and Practice, eds R. L. Watts and C. K. William (New York: McGraw-Hill Medical Publishing), 685-692.

Leblois, A., Meissner, W., Bezard, E., Bioulac, B., Gross, C. E., and Boraud, T. (2006). Temporal and spatial alterations in GPi neuronal encoding might contribute to slow down movement in Parkinsonian monkeys. Eur. J. Neurosci. 24, 1201-1208.

Lenz, F. A., Jaeger, C. J., Seike, M. S., Lin, Y. C., Reich, S. G., DeLong, M. R., and Vitek, J. L. (1999). Thalamic single neuron activity in patients with dystonia: dystonia-related activity and somatic sensory reorganization. J. Neurophysiol. 82, 2372-2392.

Lenz, F. A., Suarez, J. I., Metman, L. V., Reich, S. G., Karp, B. I., Hallett, M., Rowland, L. H., and Dougherty, P. M. (1998). Pallidal activity during dystonia: somatosensory reorganisation and changes with severity. J. Neurol. Neurosurg. Psychiatry 65, 767-770.

Levy, R., Dostrovsky, J. O., Lang, A. E., Sime, E., Hutchison, W. D., and Lozano, A. M. (2001). Effects of apomorphine on subthalamic nucleus and globus pallidus internus neurons in patients with Parkinson's disease. J. Neurophysiol. 86, 249-260.

Liles, S. L. (1985). Activity of neurons in putamen during active and passive movements of wrist. J. Neurophysiol. 53, 217-236.

Maia, T.V., and Frank, M. J. (2011). From reinforcement learning models to psychiatric and neurological disorders. Nat. Neurosci. 14, 154-162.

Marsden, C. D., Obeso, J. A., Zarranz, J. J., and Lang, A.E. (1985). The anatomical basis of symptomatic hemidystonia. Brain 108(Pt 2), 463-483.

Marshall, F. J. (2004). "Clinical features and treatment of Huntington's disease," in Movement Disorders: Neurologic Principles and Practice, eds R. L. Watts and W. C. Koller (New York: The McGraw-Hill Companies), 589-601.

Martin, J. P., and Alcock, N. S. (1934). Hemichorea associated with a lesion of the corpus luysii. Brain 57, 504-516.

McCairn, K. W., Bronfeld, M., Belelovsky, K., and Bar-Gad, I. (2009). The neurophysiological correlates of motor tics following focal striatal disinhibition. Brain 132, 2125-2138.

McHaffie, J. G., Stanford, T. R., Stein, B. E., Coizet, V., and Redgrave, P. (2005). Subcortical loops through the basal ganglia. Trends Neurosci. 28, 401-407.

Mink, J. W. (1996). The basal ganglia: focused selection and inhibition of competing motor programs. Prog. Neurobiol. 50, 381-425.

Mink, J. W. (2001). Basal ganglia dysfunction in Tourette's syndrome: a new hypothesis. Pediatr. Neurol. 25, 190-198.

Mink, J. W., and Thach, W. T. (1987). Preferential relation of pallidal neurons to ballistic movements. Brain Res. 417, 393-398.

Mink, J. W., and Thach, W. T. (1991a). Basal ganglia motor control. I. Nonexclusive relation of pallidal discharge to five movement modes. J. Neurophysiol. 65, 273-300.

Mink, J. W., and Thach, W. T. (1991b). Basal ganglia motor control. II. Late pallidal timing relative to movement onset and inconsistent pallidal coding of movement parameters. $J$. Neurophysiol. 65, 301-329.

Mitchell, S. J., Richardson, R. T., Baker, F H., and DeLong, M. R. (1987). The primate globus pallidus: neuronal activity related to direction of movement. Exp. Brain Res. 68, 491-505.

Moore, G. P., Perkel, D. H., and Segundo, J. P. (1966). Statistical analysis and functional interpretation of neuronal spike data. Annu. Rev. Physiol. 28, 493-522.

Moss, J., and Bolam, J. P. (2008). A dopaminergic axon lattice in the striatum and its relationship with cortical and thalamic terminals. J. Neurosci. 28 11221-11230.

Murphy, T. K., Goodman, W. K., Ayoub, E. M., and Voeller, K. K. (2000). On defining Sydenham's chorea: where do we draw the line? Biol. Psychiatry $47,851-857$.

Mushiake, H., and Strick, P. L. (1995). Pallidal neuron activity during sequential arm movements. J. Neurophysiol. 74, 2754-2758.

Nambu, A., Tokuno, H., and Takada, M. (2002). Functional significance of the cortico-subthalamo-pallidal 'hyperdirect' pathway. Neurosci. Res. 43, 111-117.

Nambu, A., Yoshida, S., and Jinnai, K. (1988). Projection on the motor cortex of thalamic neurons with pallidal input in the monkey. Exp. Brain Res. 71, 658-662.

Nevet, A., Morris, G., Saban, G., Arkadir, D., and Bergman, H. (2007). Lack of spike-count and spike-time correlations in the substantia nigra reticulata despite overlap of neural responses. $J$. Neurophysiol. 98, 2232-2243.

Nevet,A., Morris, G., Saban, G., Fainstein, N., and Bergman, H. (2004). Discharge rate of substantia nigra pars reticulata neurons is reduced in non-parkinsonian monkeys with apomorphineinduced orofacial dyskinesia. $J$. Neurophysiol. 92, 1973-1981.

Nini, A., Feingold, A., Slovin, H., and Bergman, H. (1995). Neurons in the globus pallidus do not show correlated activity in the normal monkey, but phase-locked oscillations appear in the MPTP model of parkinsonism. J. Neurophysiol. 74, 1800-1805.

Parent, A., Levesque, M., and Parent, M. (2001). A re-evaluation of the current model of the basal ganglia. Parkinsonism Relat.Disord. 7, 193-198.

Parkinson, J. (1817). An Essay on the Shaking Palsy. London: Sherwood, Neely and Jones.

Perkel, D. H., Gerstein, G. L., and Moore, G. P. (1967). Neuronal spike trains and stochastic point processes. II Simultaneous spike trains. Biophys. J. 7, 419-440.
Pessiglione, M., Guehl, D., Rolland, A. S., Francois, C., Hirsch, E. C., Feger, J., and Tremblay, L. (2005). Thalamic neuronal activity in dopaminedepleted primates: evidence for a loss of functional segregation within basal ganglia circuits. J. Neurosci. 25, 1523-1531.

Peterson, B. S., Pine, D. S., Cohen, P., and Brook, J. S. (2001). Prospective, longitudinal study of tic, obsessivecompulsive, and attention-deficit/ hyperactivity disorders in an epidemiological sample. J. Am. Acad. Child Adolesc. Psychiatry 40, 685-695.

Prescott, T. J., Montes Gonzalez, F. M., Gurney, K., Humphries, M. D., and Redgrave, P. (2006). A robot model of the basal ganglia: behavior and intrinsic processing. Neural Netw. 19, 31-61.

Quartarone,A., Morgante, F., Sant'angelo, A., Rizzo, V., Bagnato, S., Terranova, C., Siebner, H. R., Berardelli, A., and Girlanda, P. (2008). Abnormal plasticity of sensorimotor circuits extends beyond the affected body part in focal dystonia. J. Neurol. Neurosurg. Psychiatry 79, 985-990.

Raz, A., Vaadia, E., and Bergman, H. (2000). Firing patterns and correlations of spontaneous discharge of pallidal neurons in the normal and the tremulous 1-methyl-4-phenyl1,2,3,6-tetrahydropyridine vervet model of parkinsonism. J. Neurosci. 20, 8559-8571.

Rodriguez-Oroz, M. C., Obeso, J. A., Lang, A. E., Houeto, J. L., Pollak, P., Rehncrona, S., Kulisevsky, J., Albanese, A., Volkmann, J., Hariz, M. I., Quinn, N. P., Speelman, J. D., Guridi, J., Zamarbide, I., Gironell, A., Molet, J., Pascual-Sedano, B., Pidoux, B., Bonnet, A. M., Agid, Y., Xie, J., Benabid, A. L., Lozano, A. M., Saint-Cyr, J., Romito, L., Contarino, M. F., Scerrati, M., Fraix, V., and Van Blercom, N. (2005). Bilateral deep brain stimulation in Parkinson's disease: a multicentre study with 4 years follow-up. Brain 128, 2240-2249.

Rodriguez-Oroz, M. C., Rodriguez, M., Guridi, J., Mewes, K., Chockkman, V., Vitek, J., DeLong, M. R., and Obeso, J.A. (2001). The subthalamic nucleus in Parkinson's disease: somatotopic organization and physiological characteristics. Brain 124, 1777-1790.

Rommelfanger, K. S., and Wichmann, T. (2010). Extrastriatal dopaminergic circuits of the basal ganglia. Front. Neuroanat. 4:139. doi: 10.3389/ fnana.2010.00139

Sadek, A. R., Magill, P. J., and Bolam, J. P. (2007). A single-cell analysis of intrinsic connectivity in the rat globus pallidus. J. Neurosci. 27, 6352-6362. 
Schultz, W. (1998). Predictive reward signal of dopamine neurons. $J$. Neurophysiol. 80, 1-27.

Schultz, W. (2007). Multiple dopamine functions at different time courses. Annu. Rev. Neurosci. 30, 259-288.

Shink, E., Bevan, M. D., Bolam, J. P., and Smith, Y. (1996). The subthalamic nucleus and the external pallidum: two tightly interconnected structures that control the output of the basal ganglia in the monkey. Neuroscience 73, 335-357.

Singer, H. S., and Minzer, K. (2003). Neurobiology of Tourette's syndrome: concepts of neuroanatomic localization and neurochemical abnormalities. Brain Dev. 25(Suppl, 1), S70-S84

Starr, P. A., Kang, G. A., Heath, S., Shimamoto, S., and Turner, R. S. (2008). Pallidal neuronal discharge in Huntington's disease: support for selective loss of striatal cells originating the indirect pathway. Exp. Neurol. 211, 227-233.

Starr, P. A., Rau, G. M., Davis, V., Marks, W. J. Jr., Ostrem, J. L., Simmons, D., Lindsey, N., and Turner, R. S. (2005). Spontaneous pallidal neuronal activity in human dystonia: comparison with Parkinson's disease and normal macaque. J. Neurophysiol. 93, 3165-3176.

Steeves, T. D., and Fox, S. H. (2008). Neurobiological basis of serotonindopamine antagonists in the treatment of Gilles de la Tourette syndrome. Prog. Brain Res. 172, 495-513.

Sterio, D., Beric, A., Dogali, M., Fazzini, E., Alfaro, G., and Devinsky, O. (1994). Neurophysiological properties of pallidal neurons in Parkinson's disease. Ann. Neurol. 35, 586-591.

Stevens, J. K., and Gerstein, G. L. (1976). Interactions between cat lateral geniculate neurons. J. Neurophysiol. 39, 239-256.

Swanson, J., Castellanos, F. X., Murias, M., LaHoste, G., and Kennedy, J. (1998). Cognitive neuroscience of attention deficit hyperactivity disorder and hyperkinetic disorder. Curr. Opin. Neurobiol. 8, 263-271.
Tabbal, S. D., Mink, J. W., Antenor, J. A., Carl, J. L., Moerlein, S. M., and Perlmutter, J. S. (2006). 1-Methyl-4phenyl-1,2,3,6-tetrahydropyridineinduced acute transient dystonia in monkeys associated with low striatal dopamine. Neuroscience 141, 1281-1287.

Taha, J. M., Favre, J., Baumann, T. K., and Burchiel, K. J. (1996). Characteristics and somatotopic organization of kinesthetic cells in the globus pallidus of patients with Parkinson's disease. J. Neurosurg. 85, 1005-1012.

Tamburin, S., Manganotti, P., Marzi, C. A., Fiaschi, A., and Zanette, G. (2002). Abnormal somatotopic arrangement of sensorimotor interactions in dystonic patients. Brain 125, 2719-2730.

Tepper, J. M., Koos, T., and Wilson, C. J. (2004). GABAergic microcircuits in the neostriatum. Trends Neurosci. 27, 662-669.

Theodosopoulos, P. V., Marks, W. J. Jr., Christine, C., and Starr, P. A. (2003). Locations of movement-related cells in the human subthalamic nucleus in Parkinson's disease. Mov. Disord. 18, 791-798.

Tripp, G., and Wickens, J. R. (2009). Neurobiology of ADHD. Neuropharmacology 57, 579-589.

Turner, R. S., and Anderson, M. E. (1997) Pallidal discharge related to the kinematics of reaching movements in two dimensions. J. Neurophysiol. 77, 1051-1074.

Turner, R. S., and Anderson, M.E. (2005). Context-dependent modulation of movement-related discharge in the primate globus pallidus. J. Neurosci. 25, 2965-2976.

Turner, R. S., and Desmurget, M. (2010). Basal ganglia contributions to motor control: a vigorous tutor. Curr. Opin. Neurobiol. 20, 704-716.

Urbain, N., Gervasoni, D., Souliere, F., Lobo, L., Rentero, N., Windels, F., Astier, B., Savasta, M., Fort, P., Renaud, B., Luppi, P. H., and Chouvet, G. (2000). Unrelated course of subthalamic nucleus and globus pallidus neuronal activities across vigilance states in the rat. Eur. J. Neurosci. 12 3361-3374.

Vitek, J. L., Chockkan, V., Zhang, J. Y. Kaneoke, Y., Evatt, M., DeLong, M. R., Triche, S., Mewes, K., Hashimoto T., and Bakay, R. A. (1999). Neuronal activity in the basal ganglia in patients with generalized dystonia and hemiballismus. Ann. Neurol. 46, 22-35.

Whiteside, S. P., Port, J. D., and Abramowitz, J. S. (2004). A metaanalysis of functional neuroimaging in obsessive-compulsive disorder. Psychiatry Res 132, 69-79.

Wichmann, T. (2008). Commentary: dopaminergic dysfunction in DYT1 dystonia. Exp. Neurol. 212, 242-246.

Wichmann, T., Bergman, H., and DeLong, M.R.(1994). The primate subthalamic nucleus. I. Functional properties in intact animals. J. Neurophysiol. 72 , 494-506.

Wickens, J. (1993). A Theory of the Striatum. Oxford: Pregamon Press.

Wickens, J. R., Begg, A. J., and Arbuthnott, G. W. (1996). Dopamine reverses the depression of rat corticostriatal synapses which normally follows high-frequency stimulation of cortex in vitro. Neuroscience 70, 1-5.

Wickremaratchi, M. M., Ben-Shlomo, Y., and Morris, H. R. (2009). The effect of onset age on the clinical features of Parkinson's disease. Eur. J. Neurol. 16 450-456.

Wild, E. J., and Tabrizi, S. J. (2007). The differential diagnosis of chorea. Pract. Neurol. 7, 360-373.

Williams, Z. M., Neimat, J. S., Cosgrove, G. R., and Eskandar, E. N. (2005). Timing and direction selectivity of subthalamic and pallidal neurons in patients with Parkinson disease. Exp. Brain Res. 162, 407-416.

Wilson, C. J. (2007). "GABAergic inhibition in the neostriatum," in Progres in Brain Research GABA and the Basal Ganglia - From Molecules to Systems, ed. J. M. Tepper (Amsterdam: Elsevier), 91-110.

Wong, D. F., Brasic, J. R., Singer, H. S. Schretlen, D. J., Kuwabara, H., Zhou, Y., Nandi, A., Maris, M. A., Alexander M., Ye, W., Rousset, O., Kumar, A.,
Szabo, Z., Gjedde, A., and Grace, A. A. (2008). Mechanisms of dopaminergic and serotonergic neurotransmission in Tourette syndrome: clues from an in vivo neurochemistry study with PET. Neuropsychopharmacology 33, 1239-1251.

Worbe, Y., Baup, N., Grabli, D., Chaigneau, M., Mounayar, S., McCairn, K., Feger, J., and Tremblay, L. (2008). Behavioral and movement disorders induced by local inhibitory dysfunction in primate striatum. Cereb. Cortex 19, 1844-1856

Yoshida, M., Nagatsuka, Y., Muramatsu, S., and Niijima, K. (1991). Differential roles of the caudate nucleus and putamen in motor behavior of the cat as investigated by local injection of GABA antagonists. Neurosci. Res. 10, 34-51.

Zhang, J., Berridge, K. C., Tindell, A. J. Smith, K.S., and Aldridge, J.W. (2009). A neural computational model of incentive salience. PLoS Comput. Biol. 5, e1000437. doi: 10.1371/journal.pcbi.1000437

Zhuang, P., Hallett, M., Zhang, X., Li, J., Zhang, Y., and Li, Y. (2009). Neuronal activity in the globus pallidus internus in patients with tics. J. Neurol. Neurosurg. Psychiatry 80, 1075-1081.

Conflict of Interest Statement: The authors declare that the research was conducted in the absence of any commercial or financial relationships that could be construed as a potential conflict of interest.

Received: 31 January 2011; accepted: 20 May 2011; published online: 03 June 2011. Citation: Bronfeld Mand Bar-Gad I (2011) Loss of specificity in basal ganglia related movement disorders. Front. Syst. Neurosci. 5:38. doi: 10.3389/fnsys.2011.00038 Copyright (c) 2011 Bronfeld and Bar-Gad. This is an open-access article subject to a non-exclusive license between the authors and Frontiers Media SA, which permits use, distribution and reproduction in other forums, provided the original authors and source are credited and other Frontiers conditions are complied with 